\title{
Guinea Pig Histamine $N$-Methyltransferase: cDNA Cloning and mRNA Distribution ${ }^{\dagger}$
}

\author{
Junichi Kitanaka ${ }^{1}$, Nobue Kitanaka ${ }^{1}$, Tohru Tsujimura ${ }^{2}$, Michiko Kakihana ${ }^{2}$, \\ Nobuyuki Terada ${ }^{2}$ and Motohiko Takemura ${ }^{1, *}$ \\ Departments of ${ }^{1}$ Pharmacology and ${ }^{2}$ Pathology I, Hyogo College of Medicine, 1-1 Mukogawa-cho, Nishinomiya, Hyogo 663-8501, Japan
}

Received October 24, 2000 Accepted November 13, 2000

\begin{abstract}
We report here the isolation of histamine $N$-methyltransferase (HMT) cDNA from the guinea pig brain by the polymerase chain reaction on the basis of nucleotide sequences of rat and human counterparts. Guinea pig HMT consists of 292 amino acids, with homologies of $75.6 \%$ and $79.1 \%$ to rat and human HMT, respectively. Northern blotting analysis indicated that the $1.6-\mathrm{kb}$ guinea pig HMT transcript was expressed at various levels in different tissues at the following relative abundance: jejunum, brain $>$ lung, spleen, stomach $>$ liver, kidney. HMT mRNA localized throughout the jejunum, and it was mainly expressed in epithelial cells and in Auerbach's plexus.
\end{abstract}

Keywords: Histamine $N$-methyltransferase, mRNA, Localization

Histamine physiologically functions as a neurotransmitter in the vertebrate central and peripheral nervous systems (for review, see Ref. 1). Histamine $N$-methyltransferase (HMT, EC 2.1.1.8) is the enzyme that catabolizes histamine to $N^{\tau}$-methylhistamine to terminate histaminergic neurotransmission $(1,2)$. Thus, it is important to elucidate the tissue distribution and molecular mechanism of HMT expression to better understand the process of termination of histaminergic neurotransmission in the mammalian body. The rat kidney HMT cDNA was cloned (3), followed by the human counterpart $(4,5)$. Guinea pigs have been used as an in vivo and in vitro model for pharmacological analysis of the histaminergic system, especially for studies on allergic reactions $(6,7)$. The primary structure of its HMT protein and its genetic structure will be useful comparing the histaminergic system in this animal with those of other mammals, including humans. The human HMT protein shows $80.3 \%$ identity with the rat counterpart. Based on the molecular characterization as well as the high crossreactivity among species of antibodies against purified rat HMT protein (8), the HMT protein structure seems to be highly conserved among species. In line with these observations, we attempted to clone HMT cDNA from the guinea pig using the rat and human HMT cDNA sequences.

A male Hartley guinea pig (7 weeks of age, about $350 \mathrm{~g}$;

${ }^{\dagger}$ The complete coding sequence reported in this paper is available under the DDBJ/EMBL/GenBank accession number AB032693.

*Corresponding author. FAX: +81-798-45-6332

E-mail: takemura@hyogomc.kugi.kyoto-u.ac.jp
Nihon-Doubutsu, Co., Ltd., Osaka) was killed by decapitation and the whole brain was quickly removed. Total RNA was isolated from the brain by the acid guanidinium isothiocyanate-phenol-chloroform extraction method (9). Aliquots of $10 \mu \mathrm{g}$ of total RNA were transcribed into cDNA with the anchor primer, 5'-GCA ATT AAC CCT CAC TAA AGA ATT CAG TCA GTC A(T) $)_{17}-3$ ', using a Superscript II reverse transcriptase (Life Technologies, Inc., Rockville, MD, USA) in the presence of RNase inhibitor (Toyobo Co., Ltd., Osaka). Aliquots $(0.5 \mu \mathrm{l})$ of cDNA were applied to the first PCR mixture containing $0.25 \mathrm{U}$ of Ex Taq DNA polymerase (Takara Shuzo, Co., Ltd., Kyoto), $0.2 \mathrm{mM}$ of dNTPs, $1 \times$ buffer supplied by the manufacturer and a primer set $[20 \mathrm{pmol}$ each; forward primer: 5'GAG GAG CTT ATT TTC TGA CC-3', corresponding to the region between nucleotide 23 and 42 of the rat HMT cDNA (GenBank accession number D10693); reverse primer: 5'-CAA TTA ACC CTC ACT AAA GA-3']. PCR was initiated by incubation at $94^{\circ} \mathrm{C}$ for $5 \mathrm{~min}$, followed by 30 cycles of $94^{\circ} \mathrm{C}$ for $1 \mathrm{~min}, 58^{\circ} \mathrm{C}$ for $1 \mathrm{~min}$ and $72^{\circ} \mathrm{C}$ for $2 \mathrm{~min}$, with a final extension at $72^{\circ} \mathrm{C}$ for $15 \mathrm{~min}$ using a GeneAmp PCR System 9700 (Perkin Elmer-Applied Biosystems Japan (PE-ABI), Urayasu). Then, the second round reaction ("nested" PCR) was performed with $0.5 \mu 1$ of the first PCR reaction mixture as a template in a $10-\mu 1$ PCR reaction mixture with the same thermal cycle profile and addition of the next primer set $(20$ pmol each; forward primer: 5'-GGA ATT CAT GGA TAA GAA GC-3', corresponding to the region between nucleotide 107 and 126 of 
the rat HMT cDNA; reverse primer: 5'-CTA AAG AAT TCA GTC AGT CA-3'). The single band at about $1.1 \mathrm{~kb}$ was cut out from the $1 \%$ agarose gel after electrophoresis of the second PCR mixture and cloned into pBluescript II-KS(+) (Stratagene, La Jolla, CA, USA). Sixteen clones were selected at random to exclude the misincorporation and incomplete elongation during PCR and both strands of the cDNAs were analyzed by the cycle sequencing method using BigDye terminators (PE-ABI) in an automated DNA sequencer (model 377XL, PE-ABI). Nucleotide sequence analysis was performed with the DNASIS-Mac program (Hitachi Software Engineering Co., Ltd., Yokohama). Next, we obtained the 5 '-end of the cDNA by 5'-RACE (rapid amplification of 5 -cDNA ends) as described previously (10). For Northern blotting analysis, total RNAs of the kidney, jejunum, stomach, brain, liver, spleen and lung were obtained from male Hartley guinea pigs ( 5 weeks of age, about $300 \mathrm{~g}$ ) by the previously described method (9). Northern blotting was performed by the previously described method (11) with a 0.7-kb DNA fragment corresponding to the region between nucleotides 131 and 821 of guinea pig HMT (GenBank accession number AB032693) or a $1.0-\mathrm{kb}$ DNA fragment (containing the full coding region) of the rat glyceraldehyde-3-phosphate dehydrogenase gene (G3PDH) labeled with $\left[\alpha{ }^{32} \mathrm{P}\right]-\mathrm{dCTP}(111 \mathrm{TBq}$ $/ \mathrm{mmol}$; NEN Life Science Products, Inc., Boston, MA, USA) by the random priming method. For in situ hybridization, pieces of the jejunum were removed quickly and used for frozen sections ( $5 \mu \mathrm{m})$. The desired fragment of cDNA, corresponding to the region between nucleotides 1 and 362, was subcloned into pBluescript. cRNA probes were prepared by using a digoxigenin RNA Labeling Kit (Boehringer Mannheim, Mannheim, Germany). For hybridization, jejunal sections were incubated at $50^{\circ} \mathrm{C}$ overnight in hybridization buffer with the probes (12).

We isolated two species of guinea pig HMT cDNA with poly $(\mathrm{A})^{+}$tails at different positions of the $3^{\prime}$ non-coding region. Three possible polyadenylation signals (AATAAA) were found at reasonable positions ( 8 and 12 nucleotides 5 '-upstream in one species and 15 nucleotides 5 '-upstream in the other from the poly (A) ${ }^{+}$tail) for the two mRNA species. This is the first experimental evidence that several polyadenylation signals on HMT mRNA are actually functional in vivo. Figure 1 shows the predicted amino acid sequence of guinea pig HMT as compared with rat and human homologs. The guinea pig HMT mRNA encodes a protein of 292 amino acids, with $75.6 \%$ and $79.1 \%$ homology with rat (3) and human (4) HMT, respectively, indicating that our PCR clones were guinea pig HMT cDNA. The estimated molecular weight of guinea pig HMT is 33,710 , which is consistent with the apparent molecular size $(33 \mathrm{kDa})$ determined from Western blotting analysis (8).

As shown in Fig. 2A, HMT mRNA is most abundant in both the jejunum and brain, as predicted by Western blotting analysis (8). The result supports the suggestion that our PCR sequence seems to be functional in vivo because of the

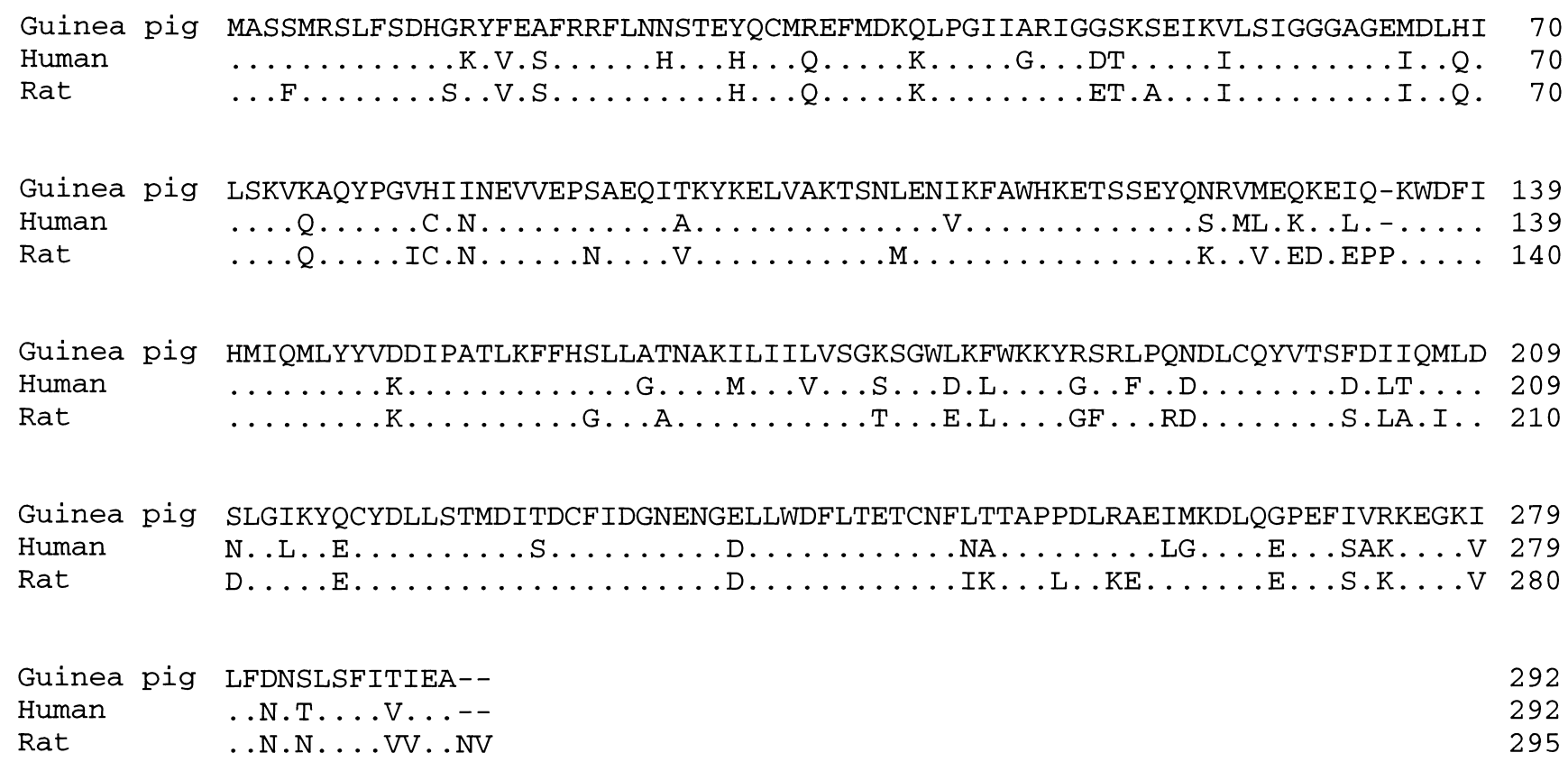

Fig. 1. Amino acid sequence comparison of the HMT of various species. The deduced amino acid sequences of the human and rat HMT are aligned with that of the guinea pig. Dots and hyphens indicate identical and deleted amino acids, respectively, compared with those of the guinea pig. 

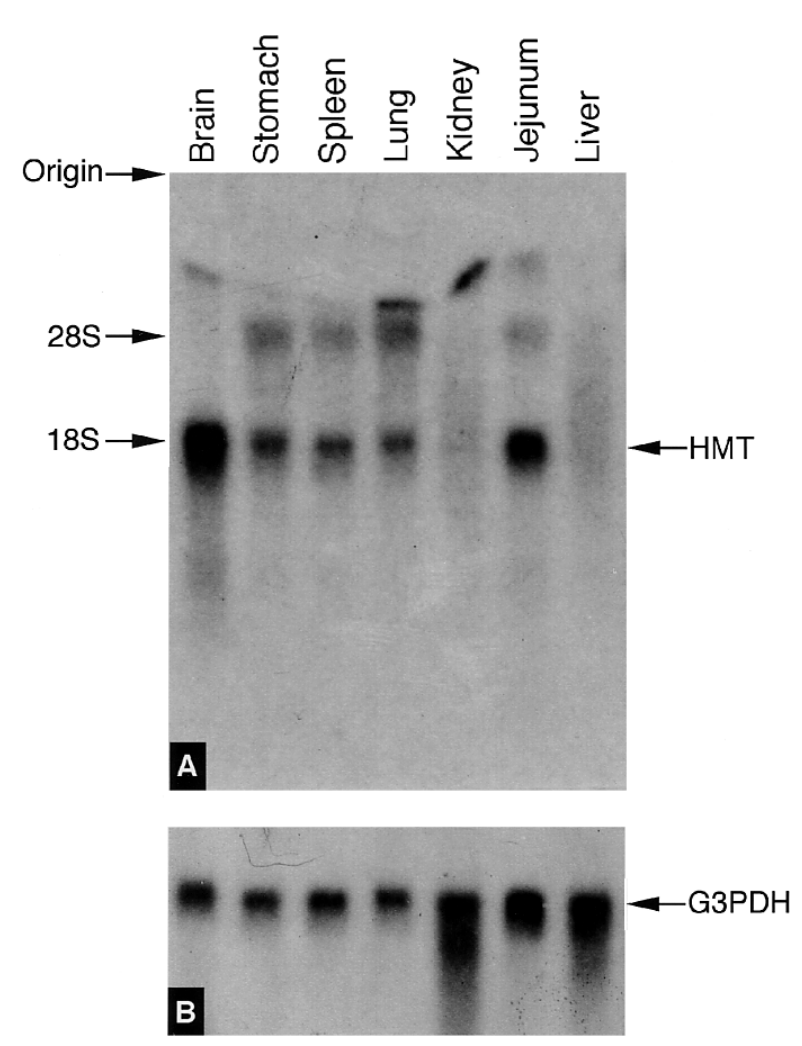

high HMT activities in the guinea pig brain and jejunum (8). The transcript size was $1.6 \mathrm{~kb}$, which was consistent with the size of human HMT mRNA (4), although three transcripts $(1.3,3.8$ and $4.0 \mathrm{~kb}$ in length) for human HMT were reported by another group (5). Guinea pig small intestine preparations have been used extensively to analyze histamine $\mathrm{H}_{1}$ receptor-mediated contraction $(13,14)$. In this tissue, HMT gene expression seems to have an important role in the regulation of contractile responses to histamine. Thus, we visualized HMT mRNA in the jejunum by in situ hybridization histochemistry. In the jejunum, HMT mRNA seemed to be expressed throughout the tissue (Fig. 3A) and localized mainly both in the Auerbach's plexus (Fig. 3: A

Fig. 2. HMT mRNA expression in guinea pig tissues. Total RNA samples, $5 \mu \mathrm{g}$ per lane, were subjected to Northern blotting analysis with the ${ }^{32} \mathrm{P}$-labeled $0.7-\mathrm{kb}$ cDNA fragment of guinea pig HMT (see text) as a probe. The autoradiogram was developed after a 30-day exposure at $-80^{\circ} \mathrm{C}$ with an intensifying screen (A). After stripping the radioactive probe off the membrane, the membrane was rehybridized with the rat G3PDH probe and then exposed for three days at $-80^{\circ} \mathrm{C}$ (B). Rehybridization of the same membrane with a rat G3PDH probe demonstrated its ubiquitous expression throughout the tissues. Positions of guinea pig $28 \mathrm{~S}(4.7 \mathrm{~kb})$ and $18 \mathrm{~S}(1.9 \mathrm{~kb})$ ribosomal RNAs are indicated.
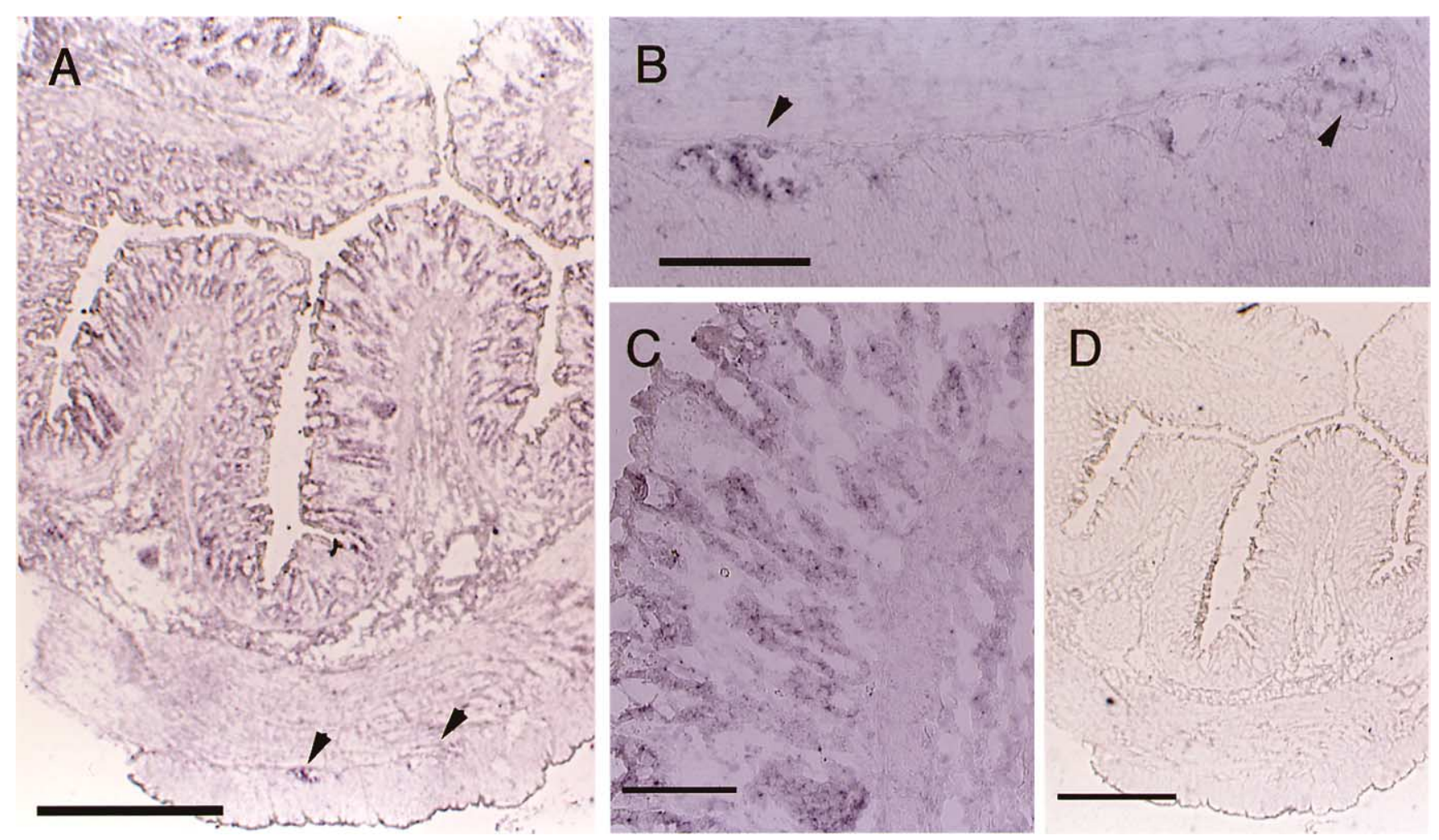

Fig. 3. HMT mRNA localization in guinea pig jejunum. The hybridization signal is purple in the picture $(\mathrm{A}-\mathrm{C})$. The positive signal was observed throughout the tissue section (A) and present mainly in Auerbach's plexus (B, arrow heads; also see Fig. 3A) and in epithelial cells (C). Use of a sense cRNA probe did not show any signal (D), as compared with the antisense probe (A). Bars: $\mathrm{A}$ and $\mathrm{D}=500 \mu \mathrm{m}, \mathrm{B}$ and $\mathrm{C}=100 \mu \mathrm{m}$. 
and B, arrow heads) and in the epithelial cells (Fig. 3C). Using a rabbit polyclonal antibody against purified bovine HMT, Tahara et al. (15) showed strong immunoreactivity in almost the same localization as that in the present study, suggesting that HMT has a crucial role in the jejunum. In guinea pig stomach, lung and spleen, the $1.6-\mathrm{kb}$ transcript was also observed (Fig. 2A), but its level of expression was lower than that in the brain. The levels of HMT mRNA expression among the tissues were quite similar to the HMT protein expression levels (8). Thus, the tissue distribution of HMT protein in the guinea pig may be a result of the expression level of the mRNA. In the rat and mouse, HMT protein is most abundant in the kidney and liver, respectively (8). This is of interest because in the guinea pig, the expression levels of HMT mRNA were quite low or undetectable in the liver and kidney (Fig. 2A). The reason why the tissue distribution of HMT protein differs among species remains to be determined in further studies, especially by analysis of the mechanism of HMT mRNA expression. For this purpose, comparative analyses of the genomic information in 5' flanking regions of the HMT genes from several mammals are currently underway in our laboratory.

In conclusion, we cloned the guinea pig cDNA homologous to rat and human HMT genes and demonstrated that the HMT protein structure is highly conserved among human, rat and guinea pig. The tissue distribution of HMT mRNA is uneven and the mRNA expression seems to be localized to the tissues in which histamine has a critical role(s). The abundant expression of HMT mRNA in both the jejunum and brain of the guinea pig suggested that HMT is an important factor in termination of histamine actions in these tissues because there is no evidence for existence of a high affinity transport element for histamine, although the mechanism(s) by which histamine is taken up from the extracellular space into the cytoplasm need to be elucidated because HMT is a cytosolic enzyme. The cDNA sequence presented in this study will be useful as a molecular probe to analyze the detailed expression pattern of HMT mRNA in guinea pig tissues.

\section{Acknowledgments}

This work was supported by Grants from the Ministry of Education, Science, Sports and Culture of Japan, the Uehara Memorial Foundation and Hyogo College of Medicine.

\section{REFERENCES}

1 Watanabe T and Wada H: Histaminergic Neurons: Morphology and Function. CRC Press, Boca Raton, Florida (1991)

2 Weinshilboum RM, Otterness DM and Szumlanski CL: Methy- lation pharmacogenetics: catechol $O$-methyltransferase, thiopurine methyltransferase, and histamine $N$-methyltransferase. Annu Rev Pharmacol Toxicol 39, 19 - 52 (1999)

3 Takemura M, Tanaka Y, Taguchi Y, Imamura I, Mizuguchi H, Kuroda M, Fukui H, Yamatodani A and Wada H: Histamine $\mathrm{N}$ methyltransferase from rat kidney: cloning, nucleotide sequence, and expression in Escherichia coli cells. J Biol Chem 267, 15687 - 15691 (1992)

4 Yamauchi K, Sekizawa K, Suzuki H, Nakazawa H, Ohkawara Y, Katayose D, Ohtsu H, Tamura G, Shibahara S, Takemura M, Maeyama K, Watanabe, T, Sasaki H, Shirato K and Takishima $\mathrm{T}$ : Structure and function of human histamine $N$-methyltransferase: critical enzyme in histamine metabolism in airway. Am J Physiol 267, L342 - L349 (1994)

5 Girard B, Otterness DM, Wood TC, Honchel R, Wieben ED and Weinshilboum RM: Human histamine $N$-methyltransferase pharmacogenetics: cloning and expression of kidney cDNA. Mol Pharmacol 45, 461 - 468 (1994)

6 Yamamoto S, Francis D and Greaves MW: Enzymic histamine catabolism in skin and its possible clinical significance: a review. Clin Exp Dermatol 2, 389 - 393 (1977)

7 Takeda N, Kalubi B, Abe Y, Irifune M, Ogino S and Matsunaga T: Neurogenic inflammation and pharmacological studies in guinea pigs: a review. Acta Otolaryngol 501, 21 - 24 (1993)

8 Takemura M, Imamura I, Mizuguchi H, Fukui H and Yamatodani A: Tissue distribution of histamine $N$-methyltransferaselike immunoreactivity in rodents. Life Sci 54, 1059-1071 (1994)

9 Chomczynski P and Sacchi N: Single step method of RNA isolation by acid guanidinium thiocyanate-phenol-chloroform extraction. Anal Biochem 162, 156 - 159 (1987)

10 Oda H, Nakabeppu Y, Furuichi M and Sekiguchi M: Regulation of expression of the human MTH1 gene encoding 8-oxodGTPase: alternative splicing of transcription products. J Biol Chem 272, 17843 - 17850 (1997)

11 Kitanaka J, Hashimoto H, Sugimoto Y, Negishi M, Aino H, Gotoh M, Ichikawa A and Baba A: Cloning and expression of a cDNA for rat prostaglandin $\mathrm{F}_{2 \alpha}$ receptor. Prostaglandins 48, $31-41$ (1994)

12 Matsusaka S, Tsujimura T, Toyosaka A, Nakasho K, Sugihara A, Okamoto E, Uematsu K and Terada N: Role of c-kit receptor tyrosine kinase in development of oval cells in the rat 2-acetylaminofluorene/partial hepatectomy model. Hepatology 29, $670-676$ (1999)

13 Winbery SL and Barker LA: Metronidazole and 5-aminosalicylic acid enhance the contractile activity of histaminergic agonists on the guinea-pig isolated ileum. J Pharmacol Exp Ther 236, $662-670$ (1986)

14 Leurs R, Brozius MM, Smit MJ, Bast A and Timmerman H: Effects of histamine $\mathrm{H}_{1^{-}}, \mathrm{H}_{2}$ - and $\mathrm{H}_{3}$-receptor selective drugs on the mechanical activity of guinea pig small and large intestine. Br J Pharmacol 102, 179 - 185 (1991)

15 Tahara A, Nishibori M, Ohtsuka A, Sawada K, Sakiyama J and Saeki K: Immunohistochemical localization of histamine $\mathrm{N}$ methyltransferase in guinea pig tissues. J Histochem Cytochem 48, $943-954(2000)$ 